\title{
Plasma Renin Activity Related to Sodium Balance, Renal Function and Urinary Vasopressin in the Newborn Infant
}

\author{
CLAUDE GODARD, JEAN-MARC GEERING, KATY GEERING AND MICHEL B. VALLOTTON \\ Laboratory of Clinical Investigation, Division of Endocrinology, Department of Medicine, University of Geneva, \\ Geneva, and Department of Pediatrics, District Hospital, Monthey, Switzerland
}

\section{Summary}

Plasma renin activity was determined in $\mathbf{2 5}$ healthy, full-term, newborn infants aged 1 day to 9 weeks. High values were found, the mean level at 1-2 days of life $(24.8 \pm 8.4 \mathrm{ng} / \mathrm{ml} / \mathrm{hr}, \mathrm{SE})$ being significantly higher than the mean levels at 7-9 days $(5.8 \pm 1.5)$ and at 4-9 weeks $(8.1 \pm 1.3)(P<0.05)$. No correlation was found between plasma renin activity and systolic blood pressure, hematocrit, creatinine clearance, serum sodium, or serum potassium. Plasma renin activity (log values) was inversely correlated with sodium intake $(r=-0.58)$ or with urinary sodium $(r=-0.44)$, and positively with urinary osmolality $(r=0.67)$. The correlations reached higher coefficients if only infants aged $\leq 9$ days were considered.

In addition, vasopressin was measured by radioimmunoassay in the urine. The daily excretion was lower in newborn infants $\mathbf{( 9 . 4}$ $\pm 1.6 \mathrm{ng} / \mathrm{m} 2 / \mathrm{day}, \mathrm{SE}$, at 1-2 days of postnatal life) than in healthy children (37.1 \pm 5.6 , and was significantly correlated with creatinine clearance $(r=0.69)$, but not with urinary osmolality.

\section{Speculation}

The postnatal changes of plasma renin activity were significantly correlated only with parameters of sodium balance and with urinary osmolality, so that one can speculate that early after birth, the renin-angiotensin system plays a preponderant role not only in sodium homeostasis, but also in water balance.

Plasma renin activity (PRA) $(8,16,23,27)$ and angiotensin II concentration (7) are relatively high in human newborn infants. PRA decreases progressively over weeks and months $(8,16,22)$; a similar trend is followed by aldosterone secretion rates (4), plasma aldosterone (4), and exchangeable sodium (19).

The cause of increased activity of the renin-angiotensin system during the neonatal period is not clear. The low sodium intake, the low blood pressure, the hypovolemia, and the increased sympathetic activity have been invoked as possible factors. On the other hand, no correlation was found between PRA and plasma aldosterone, either in cord blood $(10,26)$ or in newborn infants aged 2-3 days (26), suggesting that angiotensin II is not a predominant regulatory factor controlling aldosterone secretion at this age.

In an effort to gain insight into the interplay between renin, sodium, and renal function during the neonatal period, we have studied the relationship between PRA, sodium intake and output, urine osmolality, and glomerular filtration rate (GFR) in healthy, full-term newborns of different postnatal ages. In addition, vasopressin was determined in the urine, because limited data are available concerning this hormone in human newborns.

\section{MATERIALS AND METHODS}

This cross-sectionnal study included 28 male full term newborn infants aged 1 day to 9 weeks. They were born after uncomplicated gestation and normal vaginal delivery, with Apgar scores of 8-10. Cord was clamped uniformly at $1 \mathrm{~min}$. None of the mothers had had a salt-restricted diet or received diuretics.

All babies were healthy or recovering from minor diseases. They were divided into three groups according to age: group A: 10 infants aged 1-2 days; group B: 9 infants aged 7-9 days; group C: 9 infants aged 4-9 weeks.

Fifteen infants were breast fed (7 in group A, 6 in group B, 2 in group $C$ ) and 13 received infant formulas. Sodium intake was determined by sodium analysis in human milk (concentration range: $5.2-38.3 \mathrm{mEq} / \mathrm{liter}$ ) or calculated using data obtained from the manufacturer's laboratory (Research Laboratory, Nestlé-Alimentana S.A., Vevey, Switzerland).

Systolic blood pressure (BP) was measured before blood sampling, using the Doppler ultrasound system (Arteriosonde Roche ${ }^{R}$ ) and a $3.5 \mathrm{~cm}$ cuff applied to the right upper arm. Blood samples were obtained from antecubital or femoral vein puncture in the early morning, the infant being supine for at least $2 \mathrm{hr}$ before the procedure. Blood was collected in $10 \mathrm{ml}$ tubes containing $12 \mathrm{mg}$ of EDTA and kept on ice. After centrifugation at $+4^{\circ} \mathrm{C}$, plasma was separated and frozen at $-20^{\circ} \mathrm{C}$ until assayed.

Urine was collected over $24 \mathrm{hr}$ by spontaneous voidings in plastic bags, following the method described by Aperia et al. (2). The first urine specimen was timed and discarded. At the end of the collection period, external pressure was applied on the bladder, but additional urine was not obtained by this maneuver.

PRA was measured by the generation of angiotensin I after 1 $\mathrm{hr}$ of incubation at $37^{\circ} \mathrm{C}$ of plasma at $\mathrm{pH} 5.5$, determined by radioimmunoassay as previously described (27). The coefficient of variation is 5.9 and $6.9 \%$, respectively, for within and between assays. The accuracy is characterized by a recovery of $89.7 \pm 2.3 \%$ with a limit of detection of $0.1 \mathrm{ng} / \mathrm{ml} / \mathrm{hr}$. Vasopressin was determined by a specific and sensitive radioimmunoassay described in detail elsewhere (21). The coefficient of variation is 13 and $18 \%$, respectively, for within and between assays. The accuracy is characterized by a recovery of $69.7 \pm 1.8 \%$ with a limit of detection of $3 \mathrm{pg}$ per tube. Sodium and potassium were determined by flame photometry, osmolality by freezing point depression (Fiske osmometer) and creatinine by the Technicon Autoanalyzer method.

An additional group of 17 healthy, newborn infants of both sexes and aged 7-47 hr was studied for correlation between PRA and $\mathrm{BP}$ only.

The project was approved by the Ethical Committee for Research of the Department of Medicine, University Hospital of Geneva; informed consent was obtained from the mothers of the participants. 


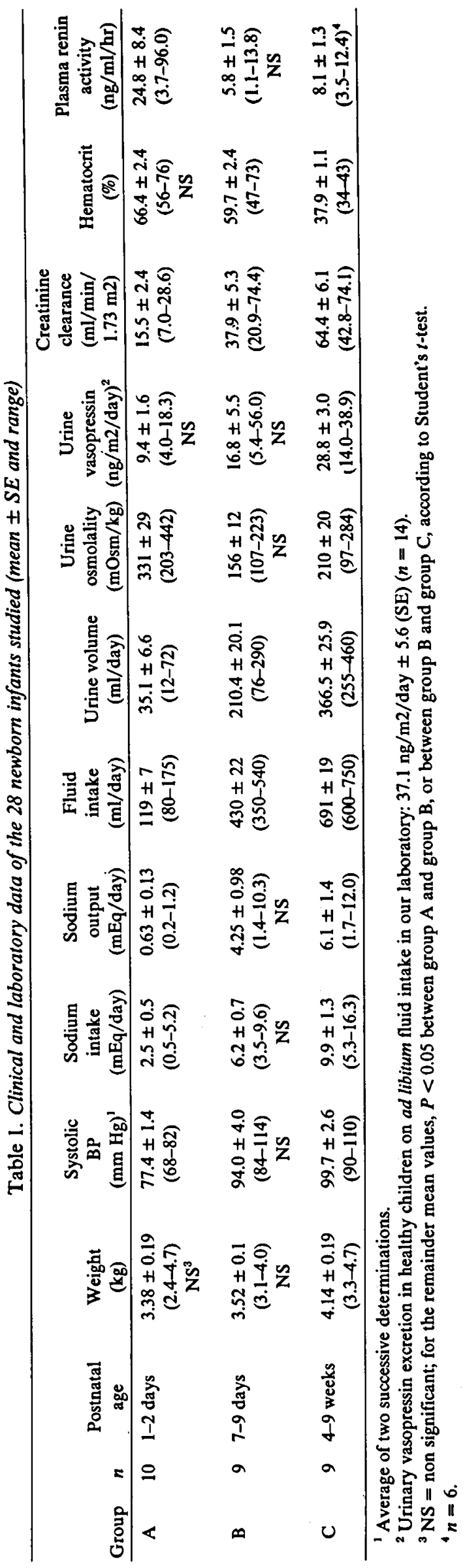

Results are expressed as mean $\pm \mathrm{SE}$ and the Student $t$-test was applied to appreciate statistical differences.

\section{RESULTS}

In the three groups of infants studied, the mean PRA was much higher than our normal values for recumbent children on regular sodium intake $(1.26 \mathrm{ng} / \mathrm{ml} / \mathrm{hr} \pm 0.16)$ and adults $(0.57 \mathrm{ng} / \mathrm{ml} / \mathrm{hr}$ \pm 0.04 ), being significantly higher in infants aged $1-2$ days (group A) than in older infants (groups B and C) (Table 1).

The scattered individual values of PRA in group A (range 3.7$96.0 \mathrm{ng} / \mathrm{ml} / \mathrm{hr}$ ) and in the additional group of 17 newborn infants aged $7-48 \mathrm{hr}$ (range $4.6-100.0 \mathrm{ng} / \mathrm{ml} / \mathrm{hr}$ ) presented no correlation with the duration of delivery, the degree of postnatal weight loss (which ranged from $0.9-7.1 \%$ ), serum sodium, serum potassium, hematocrit, or systolic BP. After log transformation, the PRA values tended to normal distribution.

The higher mean PRA in group $A$ than in groups $B$ and $C$ was accompanied by higher mean values for hematocrit and urinary osmolality and lower mean values for systolic BP, sodium intake and output, fluid intake, urine volume, and creatinine clearance (Table 1). However, the statistical analysis of individual values of 25 subjects reveals that there is no significant correlation between PRA and systolic BP, hematocrit, or creatinine clearance (our values of creatinine clearance are in agreement with those reported by others $(23,25)$, and with values of inulin clearance (13) in healthy, full-term newborns).

Log PRA was significantly inversely correlated with sodium intake $(r=-0.59, P<0.01)$ (Fig. 1$)$ and urinary sodium $(r=$ $-0.44, P<0.05)$, both expressed in $\mathrm{mEq} / \mathrm{kg} /$ day. The correlations reach higher coefficients if only groups $A$ and $B$ (infants aged $\leq$

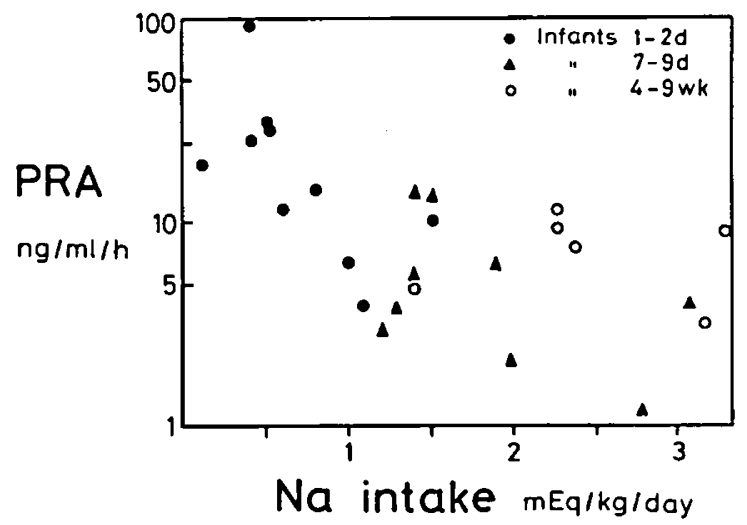

Fig. 1. Relationship of PRA (log scale) to sodium intake in 25 newborn infants aged 1 day to 9 weeks.

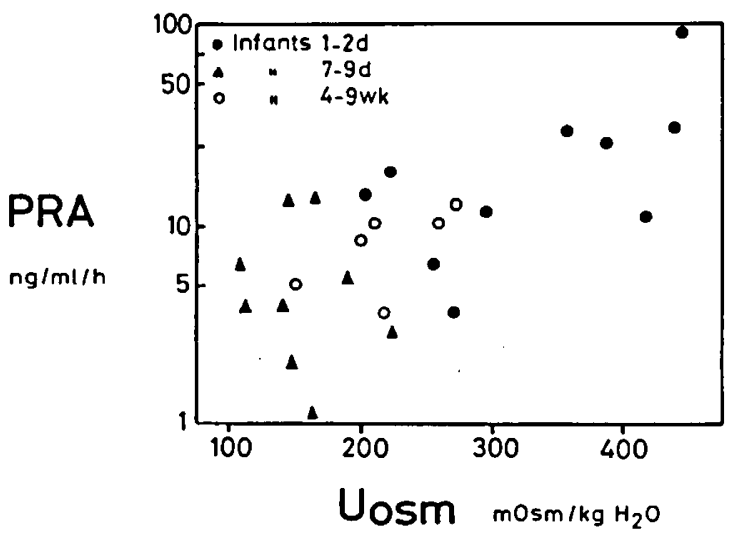

Fig. 2. Relationship of PRA (log scale) to urinary osmolality in 25 newborn infants aged 1 day to 9 weeks. 


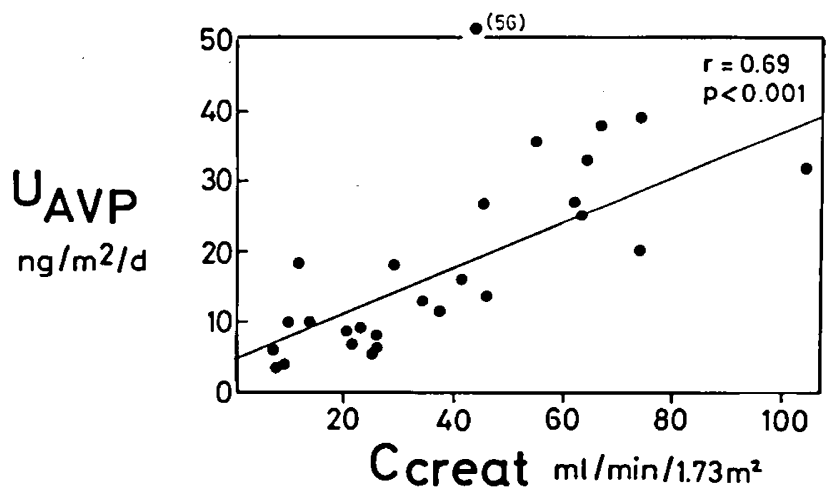

Fig. 3. Relationship of urinary vasopressin excretion to creatinine in 28 infants aged 1 day to 9 weeks.

9 days) are considered: $r=-0.74(P<0.001)$ and $r=-0.65(P$ $<0.01$ ), respectively. Urinary sodium was significantly correlated with sodium intake $(r=0.67, P<0.001)$.

As shown in Figure 2, $\log$ PRA was significantly correlated with urinary osmolality $(r=0.67, P<0.001)$ for all groups as well as for groups $\mathrm{A}$ and $\mathrm{B}$.

The mean daily urinary vasopressin excretion was higher in group $B$ than in group A, and higher in group $C$ than in group B (Table 1), but due to the dispersion of the values, these differences are not significant. After $\log$ transformation, these values tended to normal distribution. The urinary vasopressin excretion was significantly correlated with creatinine clearance (Fig. 3$)(r=0.69$, $P<0.001$ ). No correlation was found between urinary vasopressin excretion and urinary osmolality or PRA.

\section{DISCUSSION}

Our study shows a trend of PRA to decline over days after birth, thus confirming data of other publications $(8,16,23)$. It is noteworthy that infants aged 1-2 days had very scattered PRA levels. Large fluctuations of PRA within the first $48 \mathrm{hr}$ of postnatal life were also observed by others in human newborns (16) and in litters of puppies (9). The fact that individual PRA levels tend to increase even further until 48-72 hr after birth $(10,16)$ suggests the role of postnatal stimulating factors.

We cannot exclude that individual variations of blood volume may partly account for the wide range of PRA levels observed at 1-2 days in the present study. However, it is interesting to note that plasma volume has been reported to remain almost unchanged throughout day 1 to day 6 after birth (20), at a time where PRA is decreasing.

We have found no correlation between PRA and systolic BP, either when all three groups are considered, or only those newborns aged less than 2 days. This result is different from that of Broughton Pipkin and Smales (7), who have found a significant inverse relationship between circulating angiotensin II concentration and systolic BP in newborns aged 1-11 days. However, these authors have included a great number of preterm babies and ill patients, and reported systolic BP as high as $130 \mathrm{~mm} \mathrm{Hg}$, which is well above the upper limit for normal in healthy newborns (12).

The significant inverse correlation existing between PRA and sodium intake (Fig. 1) suggests that the low dietary sodium may be one of the stimuli for increased renin secretion in the neonatal period. A similar inverse relationship could be expected for plasma aldosterone, but was not found by Siegel et al. (25), at least in the range of $0.5-3 \mathrm{mEq} / \mathrm{kg} /$ day of sodium intake.

Finally, different PRA levels among healthy newborns could reflect different degrees of stimulation by the sympathetic nervous system. Plasma noradrenaline is elevated in human newborns, even in those having not suffered from perinatal asphyxia $(11,17)$. Further investigations are required to delineate the influence of plasma catecholamines in this period of life.
One may wonder what relevance has this level of activity of the renin-angiotensin system to the neonatal renal function. In fact, the effect of angiotensin II on renal function is a very complex and controversial subject. It is generally considered that in man angiotensin II reduces the GFR, the renal blood flow, sodium excretion, and free water clearance (5). In the newborn infant, the high vascular resistance, which prevails in the outer cortex (14), has been attributed to the high circulating angiotensin (16).

The full-term newborn infant has a marked capacity for distal tubular sodium reabsorption (1). As can be deduced from data of Table 1, he can achieve a positive sodium balance very soon after birth, in spite of a very low sodium intake. This can be due not only to the low GFR, but also to an effect of angiotensin II on distal tubular sodium reabsorption, either directly (15) or mediated by aldosterone stimulation. A marked elevation of plasma aldosterone has been well documented in healthy, full-term newborns (8).

A possible contributory role of the renin-angiotensin system in the concentrating mechanism of the urine in the first days after birth is suggested by the significant correlation found between PRA and urinary osmolality (Fig. 2). It seems unlikely that this effect is mediated only by a reduction of GFR, because urinary osmolality did not correlated with creatinine clearance. A direct action of angiotensin II on free water reabsorption in the tubule has been recently demonstrated in dogs (15). However, it is known that angiotensin II enhances vasopressin release (6).

From our study, it appears that the healthy newborn infant excretes appreciable amounts of vasopressin in the urine, whether it is diluted or concentrated. The significant correlation found between urinary vasopressin and creatinine clearance (Fig. 3 ) is in keeping with studies of Baumann and Dingman (3) with labeled vasopressin, showing that in the human, the source of urinary vasopressin is mainly glomerular filtration. Furthermore, recent micropunction studies revealed that vasopressin is neither appreciably secreted nor destroyed by the kidney tubules (18). As for other hormones, the urinary excretion of vasopressin may not be a true reflection of secretion when renal function is markedly impaired.

\section{REFERENCES AND NOTES}

I. Aperia, A., Broberger, O., Thodenius, K., and Zetterström, R.: Renal response to an oral sodium load in newborn full-term infants. Acta Paediatr. Scand., 61: 670 (1972).

2. Aperia, A., Broberger, R., Thodenius, K., and and Zetterström, R.: Renal control of sodium and fluid balance in newborn infants during intravenous maintenance therapy. Acta Paediatr. Scand., 64: 725 (1975).

3. Baumann, G., Dingman, J. F.: Distribution, blood transport, and degradation of antidiuretic hormone in man. J. Clin. Invest., 57: 1109 (1976).

4. Beitins, I. Z., Graham, G. G., Kowarski, A., and Migeon C. J.: Adrenal function in normal infants and in marasmus and kwashiorkor: plasma aldosterone concentration and aldosterone secretion rate. J. Pediatr. 84: 444 (1974).

5. Bock, K. D., Lever, A. F., Brown, J. J., Robertson, J. I., and Masson, G. M.: Effects of renin and angiotensin on excretion and distribution of water and salts. In: I. H. Page and J. W. McCubbin: Renal Hypertension, p. 184-203 (Year Book Medical Publishers, Chicago, 1969).

6. Bonjour, J. P., and Malvin, R. L.: Stimulation of ADH release by the reninangiotensin system. Amer. J. Physiol. 218: 1555 (1970).

7. Broughton Pipkin, F., and Smales, O. R.: A study of factors affecting blood pressure and angiotensin II in newborn infants. J. Pediatr. 9I: 113 (1977).

8. Dillon, M. J., Gillin, M. E., Ryness, J., and de Swiet, M.: Plasma renin activity and aldosterone concentration in the human newborn. Arch. Dis. Childhood, 51: 537 (1976).

9. Drukker, A., Hyo-Bok Lee, Edelmann Jr., C. M., and Blaufox, M. D.: Radioimmunoassay of plasma renin activity in small and neonatal animals. Normal values, developmental patterns and response to acute intravenous saline load. In: K. Winkel, M. D. Flaufox, and J. L. Funck-Brentano: Radionuclides in Nephrology, p. 108-113 (Georg Thieme, Stuttgart, 1975).

10. Godard, C., Gaillard, R. and Vallotton, M. B.: The renin-angiotensin-aldosterone system in mother and fetus at term. Nephron, 17: 353 (1976).

11. Godard, C., Vallotton, M. B., and Da Prada, M.: (unpublished data).

12. Goodmann, H. G., Cumming, G. R., and Raber, M. B.: Photocell oscillometer for measuring systolic pressure in newborn. Amer. J. Dis. Child., 103: 152 (1962).

13. Guignard, J. P., Torrado A., Da Cunha, O., and Gautier, E.: Glomerular filtration rate in the first three weeks of life. J. Pediatr., 87: 268 (1975).

14. Jose, P. A., Logan, A. G., Slotkoff, L. M., Lilienfield, L. S., Calgagno, P. L., and Eisner, G. M.: Intrarenal blood flow distribution in canine puppies. Pediatr. Res., 5: 335 (1971). 
15. Johnson, M. D. and Malvin, R. L.: Stimulation of renal sodium reabsorption by angiotensin II. Amer. J. Physiol., 232: F298 (1977).

16. Kotchen, T. A., Strickland, A. L., Rice, T. W., and Walters, D. R.: A study of the renin-angiotensin system in newborn infants. J. Pediatr., 80: 938 (1972).

17. Lagerkrantz, $H$., and Bistoletti, P.: Catecholamine release in the newborn infant at birth. Pediatr. Res., 11: 889 (1977)

18. Lindheimer, M. D., Reinharz, A., Grandchamp, A., and Vallotton, M. B.: Fate or arginine vasopressin (AVP) perfused into nephrons of Wistar (W) and Brattleboro (DI) rats. Clin. Res., 25: 595A (1977).

19. Loras, B., Haour, F., and Bertrand, J.: Exchangeable sodium and aldosterone secretion in children with congenital adrenal hyperplasia due to 21 -hydroxylase deficiency. Pediatr. Res., 4: 145 (1970).

20. Maclaurin, J. C.: Changes in body water distribution during the first two weeks of life. Arch. Dis. Childhood, 41: 286 (1966).

21. Merkelbach, U., Czernichow, P., Gaillard, R. C., and Vallotton, M. B.: Radioimmunoassay of 8-arginine-vasopressin. II. Application to determination of antidiuretic hormone in urine. Acta Endocrinol., 80: 453 (1975).

22. Pohlova, I., Janovsky, M., Jelinek, J., and Martinek, J.: Plasma renin activity in the newly born and in young infants. Physiol. Bohemoslov., 22: 233 (1973).

23. Sertel, $H$., and Scopes, J.: Rates of creatinine clearance in babies less than one week of age. Arch. Dis. Childhood, 48: 717 (1973).

Copyright ( 1979 International Pediatric Research Foundation, Inc. 0031-3998/79/1306-0742\$02.00/0
24. Siegel, S. R., Fisher, D. A., and Oh, W.: Serum aldosterone concentrations related to sodium balance in the newborn infant. Pediatrics, 53: 410 (1974).

25. Siegel, S. R. and Oh, W.: Renal function as a marker of human fetal maturation. Acta Paediatr. Scand. 65: 481 (1976).

26. Siegler, R. L., Crouch, R. H., Hackett, T. N., Walker, M., and Jubiz, W.: Potassium-renin-aldosterone relationships during the first year of life. J. Pediatr. 91: 52 (1977).

27. Vallotton, M. B.: Parallel radioimmunoassays of angiotensin I and of angiotensin II for measurement of renin activity and of circulating active hormone in human plasma. In: K. Federlin, C. N. Hales, J. Kracht: Immunological methods in endocrinology, p. 94-100 (Academic Press, New York, 1971).

28. The authors thank Miss M. Gourjon and Miss M. C. Dubied for excellent technical help and Miss V. Nicolet for skillful secretarial work.

29. This research was supported by the Swiss National Science Foundation (Grant no. 3.230-0.74)

30. This work was presented in part at the Fourth International Symposium of Paediatric Nephrology, Helsinki, 1977.

31. Requests for reprints should be addressed to: Claude Godard, MD, Department of Pediatrics, District Hospital, CH 1870 Monthey, Switzerland.

32. Received for publication March 14, 1978.

33. Accepted for publication June 19, 1978. 